\title{
The Need to Belong: a Deep Dive into the Origins, Implications, and Future of a Foundational Construct
}

\author{
Kelly-Ann Allen ${ }^{1,2}$ (D) DeLeon L. Gray ${ }^{3}$. Roy F. Baumeister ${ }^{4} \cdot$ Mark R. Leary $^{5}$
}

Accepted: 16 July 2021 / Published online: 31 August 2021

(C) The Author(s), under exclusive licence to Springer Science+Business Media, LLC, part of Springer Nature 2021

\begin{abstract}
The need to belong in human motivation is relevant for all academic disciplines that study human behavior, with immense importance to educational psychology. The presence of belonging, specifically school belonging, has powerful long- and short-term implications for students' positive psychological and academic outcomes. This article presents a brief review of belonging research with specific relevance to educational psychology. Following this is an interview with Emeritus Professors Roy Baumeister and Mark Leary, foundational pioneers in belonging research which reflects upon their influential 1995 paper, "The need to belong: Desire for interpersonal attachments as a fundamental human motivation," to explore the value and relevance of belonging for understanding human behavior and promoting well-being.
\end{abstract}

Keywords Belonging; Sense of belonging; Motivation · Need to belong · Interpersonal relationships $\cdot$ Connection

Our understanding that belonging and the desire for interpersonal relationships have been shaped by decades of work that emerged from social psychology. While this work cannot be credited as founding this area of belonging research, it can certainly lay claim to creating a groundswell around the topic and solidifying our knowledge of the importance of belonging as a universal human need. The aim of this paper is

Kelly-Ann Allen

Kelly-ann.allen@monash.edu.au

1 School of Educational Psychology and Counselling, Faculty of Education, Monash University, Clayton, Australia

2 Centre for Wellbeing Science, Melbourne Graduate School of Education, The University of Melbourne, Parkville, Australia

3 Department of Teacher Education and Learning Science, North Carolina State University, Raleigh, NC, USA

4 School of Psychology, University of Queensland, St Lucia, Australia

5 Psychology and Neuroscience, Duke University, Durham, NC, USA 
to (1) provide a brief, focused review on the topic of belonging and how it relates to important work in educational psychology and (2) examine the seminal work of Emeritus Professors Roy Baumeister and Mark Leary, pioneers of belonging research, through an extensive interview that centers around their 1995 contribution, "The need to belong: Desire for interpersonal attachments as a fundamental human motivation." Our goal is to reflect on their widely cited belongingness hypothesis (Baumeister \& Leary, 1995), highlight their noteworthy work over a quarter of a century, discuss the implications of belonging research for educational psychology, and identify implications for scholars who wish to carry this work forward.

Belonging - conceptualized broadly as a fundamental human need-is a complex construct due to its multifaceted components, predictors, and outcomes (Allen et al., 2021a; Baumeister \& Leary, 1995). A very brief synthesis of the bulk of the work that has been done on belonging might read: belonging is good. The absence of belonging? Well, that is bad. Indeed, most of the research literature before 1995 really did not go much further than this. A step change took place that year when two leading social psychologists, Roy Baumeister and Mark Leary, suggested that belonging is not only good but that the desire to belong is a deeply rooted human motivation that, underpinned by our ancestral origins, permeates our thoughts, feelings, and behaviors. At the same time as Baumeister and Leary were carrying out their pioneering work in 1995, Kelly-Ann Allen and DeLeon Gray (also authors of this paper) were embarking on their own personal self-discovery concerning the nature of belonging; first-hand, in high school and middle school! It is in applied contexts, such as schools, that the experience of belonging can be seen as a dialectical construct that both straddles and synthesizes good and bad elements (Allen et al., 2018a). Belonging is often painted in unequivocally positive terms by contrasting it to the awkward and imperfect contranym "not-belonging" or to notions such as social isolation, ostracism, and rejection. However, the potential ill effects of belonging can be highlighted if we consider situations such as those in which some groups of people forge a sense of belonging by othering members of other groups (Allen, 2020a). Belonging can materialize in forms that satisfy the motivation to belong but threaten the healthy functioning of the individual and the cohesion of society. Moving closer to one group of people can often involve moving further apart from others. Nearly 30 years after being set on its new course, research on belonging now has an important role to play in addressing some of society's most complex challenges, such as loneliness, caring for an aging population, various forms of social and political "tribalism," and school violence, all of which are rooted partly in a desire to belong (Allen, 2020b; Allen, et al., 2021b; Lim et al., 2021). Moreover, belonging research has broad relevance to educational psychology, considering the critical role of belonging on student wellness, achievement behavior, and performance (Allen et al., 2021c).

The specific application of belonging research to educational psychology is often oriented around the terms school belonging (Allen, et al., 2021b; Anderman, 2003; Hamm and Faircloth, 2005; Pittman \& Richmond, 2007) and university or college belonging (Arslan, 2021; Slaten et al., 2016, 2020), although other constructs such as school connectedness, community, membership, and bonding are also used (Allen \& Bowles, 2012; Korpershoek et al., 2020). The most common way of describing 
belonging in educational settings in the literature references a student's feelings of being accepted, respected, and valued - an understanding that first emerged from the work of Goodenow and Grady (1993). Subsequent work has considered the socioecological interactions with school belonging to expand the definition to involve multiple systems (Allen et al., 2016; Allen et al., 2021e), and recent pioneering work has emphasized the importance of school belonging for all students, positioning it as a fundamental human right (Gray et al., 2018). This work acknowledges that, within our efforts to promote belonging, equity, and inclusion in schools, many voices are still not heard, and these voices need to be empowered and amplified (Faircloth, 2021; Gray et al., 2020).

A broad spectrum of empirical studies highlights the benefits of belonging for students. Parr et al. (2020) identified belonging as the largest known correlate with symptoms of depression, accounting for nearly $50 \%$ of its variance. Other research has found benefits for mental health and emotional well-being (Allen et al., 2018b; Arslan, 2018; Arslan \& Allen, 2021; Arslan et al., 2020; Li \& Jiang, 2018; Šeboková et al., 2018; Zhang et al., 2018), academic success, hardiness, social inclusion, and life satisfaction (Abdollahi et al., 2020; Arslan et al., 2020; Brooms, 2016; Palikara et al., 2021; Scorgie \& Forlin, 2019), self-esteem and associated positive outcomes (Foster et al., 2017; Peng et al., 2019), lowered school dropouts (Organisation for Economic Co-operation and Development [OECD], 2018; Uslu \& Gizir, 2017), reduced likelihood of absenteeism, misconduct, school disengagement or students leaving school early without a qualification (Ibrahim \& El Zaatari, 2019; Korpershoek et al., 2020; OECD, 2018), decreased feelings of alienation, isolation and disaffection or low social integration and social exclusion (Arslan et al., 2020; Palikara et al., 2021), and better performance and self-belief in abilities to succeed academically (Chun et al., 2016; Holloway-Friesen, 2019). Recent research shows that a sense of school belonging is a significant predictor of future employment, education, and training (NEET) (Parker et al., 2021), even up to 15 years post-school, and our understanding of the role that school belonging plays in the psychosocial adjustment of students who have experienced traumatic events or other forms of stress (Cardeli et al., 2020; Zhang et al., 2021) has immense implications for educational practice, as well as therapeutic benefits.

The body of literature concerned with belonging in schools has predominantly been shaped, inspired, and conceptualized from the understanding that belonging is a fundamental human need, and we have two people, in particular, to thank for this understanding. Professor Roy F. Baumeister, Ph.D., an emeritus professor of psychology at the University of Queensland, with ongoing connections to Florida State University, the University of Bamberg (Germany), and the University of Bremen (Germany) and Professor Mark R. Leary, Ph.D., an emeritus professor of psychology and neuroscience at Duke University. Both individually and together, Baumeister and Leary have made significant contributions to psychology by building a solid empirical and conceptual understanding of our innate need to belong. In 1995, Baumeister and Leary wrote, "The need to belong: Desire for interpersonal attachments as a fundamental human motivation," which has become the most recognized and cited work on the topic of belonging. Their work has been instrumental in shaping a new generation of belonging researchers who reference their 
foundational scholarship in belonging research spanning from social network analysis (Bjorklund \& Daly, 2021) to brief psychological interventions (Walton \& Brady, 2017).

The aim of the second part of this paper is to reflect upon "The need to belong: Desire for interpersonal attachments as a fundamental human motivation" with Baumeister and Leary and to explore its relevance and value for educational psychology and researchers, students, and practitioners interested in belonging.

\section{Interview Approach}

This interview draws from the significant work of Baumeister and Leary over the last quarter of a century to provide insights into the origins of their ideas, explore their views of the state of belonging research today, and identify implications for scholars who wish to carry this work forward. The interview took place over email between January and May 2021. The interview questions were divided between the interviewees, who each received 7 of the 14 questions. They each responded to the seven questions in writing before their responses were shared, and the seven questions were swapped so that each respondent could build on the answers of the other respondent. The questions were written by two authors (Allen and Gray), both educational and developmental psychologists whose research on belonging has been influenced by the Baumeister and Leary (1995) article.

1. Your 1995 Paper, "The Need to Belong: Desire for Interpersonal Attachments as a Fundamental Human Motivation" Has Been Cited Nearly 30,000 Times. What Is It About This Paper that Made It so Successful?

RB: Papers are cited most when they are useful to other scientists in doing and writing up their work. The "need to belong" makes a basic point about human motivation that is useful for developing many other theories about specific aspects of interpersonal behavior. Specifically, the point is that the human mind contains a basic and nearly universal drive to form and maintain relationships with some other people. As a contrasting example, Freud said the two basic motivations are sex and aggression, and pretty much all else derived from those. We made a case that the need to belong is at least as fundamental and pervasive as those motivations.

When writing the paper, Mark and I had no idea it would be so widely cited, and indeed when we received the Society of Experimental Social Psychology (SESP) Impact Award for it, I recall we said we were surprised it had reached close to 10,000 citations. I do not regard this paper as a brilliant new idea or a transformative insight. At best, we took an idea that had been in the background (dating back at least to Freud) and moved it into the foreground, as a major driver of much of social life. We were surprised by how strong and consistent, and diverse the evidence was. I suppose many readers were also.

ML: In addition, I think many behavioral researchers are hungry for broad, overarching perspectives that help us understand a wide range of disparate psychological phenomena. After the grand theories of the early twentieth century - such as 
psychoanalytic theory and behaviorism - fell short because they tried to explain almost everything, many psychologists retreated to smallish theories of specific phenomena. But these micro-theories were often unsatisfying because they focused so narrowly on particular effects. As a mid-sized theory, the Need to Belong was able to explain and integrate a very wide swath of human thought, emotion, and behavior under a single umbrella but made no pretense of trying to explain everything people do. In a sense, it was a Goldilocks-sized theory that seemed "just right" to many researchers.

2. Thinking Back to 1995 Paper, What Were the Vision and the Motivation Behind Writing "The Need to Belong: Desire for Interpersonal Attachments as a Fundamental Human Motivation?" Tell Us a Bit More About Your Careers in that Year and What You Had Been Researching Previously.

RB: The vision emerged slowly. During the 1980s both of us attended the small social psychology conferences hosted by Bibb Latané at Nags Head. We generally attended the one on the self, which also brought the trio of Terror Management Theory researchers, so there were always three talks on their ideas. Among them was the central point that anxiety was basically linked to the human fear of death and awareness of mortality. I did not know much about anxiety, but I understood that many people suffered from anxiety, and I could not quite accept the view that the root of their suffering was the fact of eventual death. With Dianne Tice, I reviewed the research literature on anxiety. It turned out that a moderate amount of anxiety does have themes of death and injury — but by far the biggest theme was being socially rejected, excluded, or otherwise condemned to being alone. Tice and I wrote up the review, which was published as a target article in the Journal of Social and Clinical Psychology (Baumeister \& Tice, 1990). The commentaries were mostly constructive and fascinating, except for a predictably hostile and defensive one by the Terror Management guys. Mark contributed an intriguing commentary. When that was done, the next time we attended a conference together, Mark made a crucial remark, which was that he thought Diane and I were right about anxiety - but that we had only scratched the surface. He thought there was plenty more to be found with regard to the motivation to avoid being alone.

We had several subsequent conversations about how to develop these ideas further: a small conference? An edited book? Eventually, we came around to the idea of writing a review/theory article. My point with this story was that the "need to belong" paper might well never have been written, and it took us a long time to come round even to the idea of writing it.

Once we started collecting information, we were impressed by its extent. Fortunately, Mark knew plenty of things I didn't, and perhaps vice versa, so the evidence for the paper shaped up in strong ways. We had cognition, emotion, behavior, physical health, mental health, and more. The journal review process was rigorous and strenuous, but we managed to satisfy them, and the paper was published.

In response to your question about the vision behind the paper, I can say it became a focus for one of the themes of my career, which is the fundamental importance of interpersonal relations. It may seem obvious that social psychologists emphasize 
interaction, but actually, they do not. In the 1970s, during my training, the field emphasized processes inside the single mind (cognitive dissonance and attributions were the most studied). That tendency is still strong. The approach among my teachers was that it is important to understand what goes on inside the mind, and social interactions are a product of those inner processes. Over the years I have come to emphasize the opposite point of view: Inner processes serve interpersonal functions. What happens inside the single mind is a learned or evolved means of enabling us to work together. Nowadays this view has gained recognition, thanks in particular to the evolutionary psychologists who identify communication and cooperation as the huge advances that set humans apart from other species. This means we evolved to use advanced social interaction as our strategy for survival and reproduction.

ML: My interest in people's desire for acceptance and belonging emerged from my work on people's concerns with how they are perceived and evaluated by others. I had spent the first several years of my career studying how people manage others' impressions of them (self-presentation) and their reactions when they don't think they'll make the impressions they would like to make (social anxiety and embarrassment). Roy and Dianne's article on social exclusion and anxiety made me realize that many of people's concerns with others' views of them are rooted in concerns with social acceptance. In our initial late-night conversation at the Nag's Head conference, we began to cast an even larger net on all of the ways that a desire for belonging might affect behavior, and the project emerged from there.

I should add that serendipity played a big role in our collaboration. We obviously needed to meet in person to map out the ideas for the paper (remember, this was in the days before Zoom calls or even email), and Roy happened to be doing a sabbatical that year at the University of Virginia, so we were within driving distance of each other. Not only that, but we discovered that his sister lived around the corner from me. So, we were able to meet face-to-face, scribbling ideas on giant sheets of paper that were strewn across my living room in a big stream-of-consciousness outline.

3. Could You Tell Us About the Belongingness Hypothesis and Whether It Is More or Less Relevant Today than It Was 30 Years Ago?

RB: The core point of the belongingness hypothesis is that people have an innate motivational drive to form and maintain interpersonal bonds with other people. We called belonging a "need" rather than merely a "desire" because people who fail to satisfy it suffer various mental health and physical health deficits. We framed it in terms of forming one-to-one close relationships, but it can probably be satisfied by belonging to larger groups and organizations. These desired social bonds have two aspects: frequent positive or neutral (just not negative) interactions, and an ongoing framework of mutual caring.

I have no reason to think this is any more or less relevant than it was 30 years ago, or even a thousand years ago. The social environment may have changed, opportunities for connection have expanded, relationships take new forms - but the basic motivational drive is probably the same and likely equally important now as in the past. 
Perhaps the most dramatic change from 30 years ago is how much online interaction there is. Dealing with people online has become a major part of everyday life, for better and for worse. Online interactions present new opportunities for social connection but also new dangers and problems. My Chinese colleague Dong Liu and I have published several meta-analyses regarding online interactions, and these contain both good and bad news. In particular, some people use online interactions as a substitute for live interactions, and this does not seem to work very well so that their loneliness and other problems are high.

Meanwhile, other people use online interactions to enrich relationships that begin offline (i.e., live in person), and this really does work well. One way I illustrate this is that if you met someone briefly at a party or at work 40 years ago, unless you really connected, you'd likely not maintain any connection. But today, you can exchange emails, and a relationship might develop.

Other problems have been suggested by my former protégé Jean Twenge. She has written extensively about how young people have changed over time, with seemingly contradictory increases in both self-esteem and anxiety. She has concluded that spending so much time online has a major downside for today's young people. People present idealized versions of their lives on social media - and people who look and believe those idealized images start to feel down about their own imperfect lives. Online interaction has also greatly increased the opportunities for bullying and brutal mob action, for spreading false information about other people, and for making a slight mistake that will damage one's identity for years to come. The recent news stories about the Smith student who ruined several people's lives with false online accusations of racism (see Alexander, 2021; Powell, 2021) show these new threats to belongingness affect adults too.

ML: I agree with Roy that there's no reason to think that the need to belong is any more or less relevant than before. However, cultural changes and social events over the past 30 years have certainly changed the ways in which people navigate issues of acceptance and belonging (such as the online interactions that Roy described) and also brought to light the role of belonging in phenomena that we hadn't previously considered. For example, in the United States, the three most noteworthy events of 2020 - the COVID pandemic, increased attention to racial justice, and the presidential election and its aftermath - each showed ways in which the motive to establish social connections and to be accepted — and the failure to achieve adequate belonging — can influence not only individual behavior but also social movements.

4. What Is Your Current Thinking About the Belongingness Hypothesis? If You Wrote a 2.0 Version of This Paper Today, What Would You Emphasize?

RB: The core ideas remain the same. If I were writing it today, the main thing would be to add belongingness in groups rather than emphasizing pair-bond relationships. Another might be individual differences. Mark has developed a scale to measure the strength of a person's need to belong. When I first heard about it, I asked him whether he still thought everyone had the need to belong. He said he did - but the strength of the drive varied substantially among persons. Of course, he was right. 
So, I think the ideas have developed in different directions and eventually shaped my thinking in unexpected ways, but the original idea of the importance of the need to belong has remained largely intact in my thinking.

ML: I would begin by clarifying our terminology. Although our article focused mostly on dyadic relationships, we used the term "belong," which connotes having membership in a group of one kind or another. We don't normally talk about people "belonging" to their neighbor, best friend, or romantic partner. I recall Roy and I talking about these terms at the time but can't reconstruct why we settled on "belong," which may not have been the most accurate, precise, and unambiguous way to characterize this motive. Because of this ambiguity in the "need to belong" moniker, I tend to use the more cumbersome term "need to be accepted and belong" to make it clear that I'm referring to a desire for social connections with both individuals and members of a group.

If I were revising the article today, I would also make it clearer that not all efforts to be accepted or to belong arise from the universal, evolved need that we described. Although a need for social connection is an inherent part of human nature, some efforts to be accepted or to belong reflect efforts to achieve specific goals rather than an evolved need. For example, a business person might seek membership in a business association not because he or she desires acceptance or belonging per se but rather to make contacts that will increase business. The person doesn't particularly care about this particular organization or these particular people, and in fact, he or she might detest having to go to group meetings. He or she is simply doing something that will be good for business. In cases of instrumental efforts to be accepted or to belong, the motivational impetus is not a desire for acceptance or belonging per se, so the evolved need to belong is not necessarily involved.

5. What Have Your Subsequent Studies and Related Lines of Research Revealed About Belonging?

RB: Both Mark and I spent many years after that paper was published studying social rejection. After all, being rejected thwarts the need to belong. My initial theory was that this would produce emotional distress, which might lead to some behavioral changes. Yet, in study after study, we found big behavioral changes but no reports of emotional distress. Among other things, this led me to reconsider the relationship between emotion and behavior, resulting in a major theory article on emotion, and a meta-analysis of every study in Journal of Personality and Social Psychology (JPSP) over several decades that reported analyses of mediation by emotion (Baumeister et al., 2007; DeWall et al., 2016). It seems emotion does not usually function as a direct cause of behavior.

The absence of distress after lab rejections (also confirmed by a meta-analysis of a couple hundred lab studies of rejection) puzzled me for years until we came across MacDonald and Leary's (2005) great review of evidence showing a lack of pain sensitivity among rejected or excluded animals. Panksepp had proposed that when animals evolved to become social, they did not necessarily develop new organs to deal with social life. Rather, evolution retro-fitted existing mechanisms to respond to social events. Many animals have a kind of shock reaction of physical numbness 
right after injury. This presumably evolved to enable an injured or wounded animal to escape from a dangerous situation without being hampered by intense pain. It seems social injuries such as rejection produce the same kind of shock reaction. After I learned what MacDonald and Leary were doing, DeWall and I (2006) ran studies to see whether rejected humans showed a loss of sensitivity to pain, and they did. The pain numbness also correlated with emotional numbness.

One of Mark's most important ideas based on belongingness was that self-esteem is involved and may serve as an internal measure of one's belongingness status or at least potential interpersonal appeal (i.e., relational value, as he recently discussed it). I was happy to work with him on one paper on this, but he has done plenty more. Of course, there is more to self-esteem than that, but it's nevertheless central and important. Some recent work by a European group suggests that self-esteem is based not just on belongingness but also on social status, a theory they label "hierometer," as in measuring one's actual current or anticipated future position in the hierarchy. We had assumed that rising in the hierarchy serves belongingness. For example, people at the bottom of the hierarchy are easily fired or discarded, but those at the top are more secure. Nevertheless, it does seem right to me that hierarchy matters also, and somewhat independently of belongingness. The two theories go together pretty well.

Another advance involved gender. Right after the need to belong was published, I was asked to review a theory article proposing that many gender differences are based on the fact that women desire connection but men don't. I was sceptical, because I thought everyone has the need to belong. The authors (Cross and Madson) made a reasonably good case, so I advocated publishing it, but it prompted me to consider the need to belong in relation to gender. I wrote to the editor that all their evidence could be interpreted a different way. Rather than saying that men don't care about social connection, the evidence indicated to me that men are more oriented toward larger social groups, while women give priority to one-to-one intimate relationships. Subsequent work by Gardner and Gabriel supported this conclusion.

Around this time, I was perturbed by Freudian theory, which had been an inspiration to me during my student days (and helped persuade me to study psychology). I noticed it was largely fading from psychology - yet many other fields still relied heavily on Freud's ideas. I began to think that this was because Freud offered a broad, coherent system by which to understand human nature, which scholars in other fields could master and use for their own work. The piecemeal research approach had led to many advances in psychological knowledge but no coherent theory was emerging. So, I devoted one of my sabbaticals to the project of developing a coherent overview theory of the human mind based on modern research findings. I read a great deal and struggled to make sense of it in a bigpicture kind of way. I finished the book and sent it off to the publisher but was still struggling to understand what was the coherent message. And then, one evening, it came to me: The human psyche seemed remarkably well designed for group social interaction. At first, this surprised me because there is a long intellectual tradition of seeing society and the individual as fundamentally in conflict (as Freud himself did, such as in his classic Civilization and Its Discontents). Instead, there I was concluding that the human mind was naturally disposed toward living in society, even though there are, of course, many conflicts and problems. I had 
to write to my publisher and ask to cancel the book because I needed to revise it around this idea. The book came out somewhat later and has been the foundation of my thinking ever since. Its title, The Cultural Animal, argues that most of the distinctively human traits - what makes us human - are essentially adaptations to make culture possible and enable people to prosper from it.

The cultural animal idea builds on the need to belong. It's not just that we like to have relationships with others. Rather, we evolved to be able to form and profit from new kinds of relationships, including those in large groups, including ones that enable us to have mutually beneficial interactions with total strangers - something many of us do every day, but which is almost entirely absent in the animal world.

ML: I have been most surprised by how rampant the need to belong is. Although Roy and I discussed an exceptionally broad range of phenomena in our original article, I have nonetheless been surprised when concerns about acceptance and belonging cropped up in unexpected places.

Perhaps most notably, I have been impressed by how much of human emotion is linked to people's concerns with belonging and acceptance. Indeed, several emotional mechanisms respond to real or potential threats to belonging. Two of themsocial anxiety and jealousy_are largely anticipatory, alerting people to the possibility that their social connections may be in jeopardy. In contrast, hurt feelings arise when people perceive that their relational value to other people is lower than they desire. The so-called self-conscious emotions-embarrassment, guilt, and shameseem to be reactions to making undesired impressions that lower one's relational value and acceptance to other people. And loneliness is often fueled by the sense that people who accepted us are not currently available.

Looking at this work as a whole, I can't escape the conclusion that nature wanted to be certain that human beings paid adequate attention to potential and actual rejection in whatever form it might take. The fact that human beings evolved an arsenal of mechanisms that respond to real, potential, and imagined losses of acceptance and belonging supports the notion that being valued and accepted was exceptionally important throughout human evolution. Emotions signal the presence of events that have potentially important implications for an animal's well-being, thereby motivating them to focus on concerns that might require immediate attention.

6. You Are Both Social Psychologists, Yet Your Work on Belongingness Has Transcended Disciplines and Fields. What Relevance Does Your Work Have for Educational Psychology?

RB: I recently wrote an integrative commentary on a special issue of the Australian Journal of Psychology on belongingness among students (Baumeister \& Robson, 2021). Some key conclusions: The need to belong was shaped in the psyche by an evolutionary environment that differs in important ways from the modern school, creating a kind of psychological mismatch. Differences include encountering far more different people and having much more turnover in relationships, so each bond is contingent and tentative rather than permanent. School children spend much more time with same-age peers, and also with people of different races and genders, than 
their ancestors. The online environment also presents novel challenges and opportunities for belonging.

There has been much discussion about whether self-esteem is important for education, and self-esteem is substantially (though probably not entirely) rooted in belongingness. Marsh's work has made a strong case that with education, it's the area-specific self-esteem that matters, not global self-esteem. Whether belongingness has anything to do with area-specific self-esteem (e.g., believing oneself good at math or reading) may be worth exploring. My impression is that excessive concern about self-esteem in school policies has been very destructive for education, perhaps especially for boys. The related policies include social promotion for students who have, in fact, not mastered the year's material; the abolition of ability grouping; grade inflation; and a general reluctance to criticize. Note that social promotion for students is presumably motivated by concern for the student's welfare and belongingness: The administrators think it would damage the student's selfesteem to make him or her repeat a year, plus the student would lose the circle of friends and have to make new ones. But Marsh's research suggests the reality is the opposite (see Marsh, 2016; Marsh et al., 2017). Students who repeat a year make new friends easily and, being older and having been through the material already, do fine with their new group. Their grades also improve and stay improved for years thereafter - in contrast to the socially promoted ones, who continue to perform badly year after year.

Still, belongingness remains an important driving force. If we can explore new ways to harness that motivation to striving for superior academic achievement, it would benefit plenty of individuals as well as society as a whole.

ML: I'll simply add that, academic achievement aside, belonging plays an important role in the degree to which students are motivated to go to school in the first place. School can be a very lonely and unhappy place for students who feel they don't belong, with implications for motivation, attendance, and depression. In fact, low belonging in school may be a central cause of depression in children and adolescents. Steve Asher's work on loneliness and belonging in elementary school, middle school, and college suggests that helping students meet their need to belong may have far-reaching effects on both academic and nonacademic outcomes.

7. What Are The Developmental Considerations for Belonging in Young People? Are They the Same as Adults?

ML: We're not developmental psychologists, so others might be able to answer this question better than we could. But my sense is that once children start functioning in their own social groups, the same processes are involved. Children and adolescents want to be relationally valued and to belong, they work hard to be included, and they suffer mightily when they are rejected.

That being said, people's approach to belonging may be moderated by their stage of life. In general, our connections with other people become more stable and less tenuous as we get older because we gravitate into social lives in which we are mostly accepted by the people with whom we regularly interact. That's generally not the case for younger people. Young people often face a regularly shifting pattern of 
friends, acquaintances, and group memberships and cross paths with many more people each day (in school, for example) than most adults do. Although adults certainly experience upheavals in their friendships, close relationships, and relationships at work, they tend to settle into periods of relative stability in which they don't have to worry consciously on a daily basis about their social acceptability to the important people around them.

On top of that, as people get older, they seem to become more discerning about when acceptance and belonging do and do not matter. In adolescence, indifference or exclusion by virtually anyone can be traumatic, but with experience, adults come to realize that what most people think about them doesn't really matter all that much. They are certainly still very troubled by important rejections, of course, but they get better at ignoring the reactions of people whose acceptance doesn't really matter.

RB: Adolescence may indeed be the most difficult time for belongingness. For very young children, belongingness is centered on the family, which one hopes is fairly stable. By the teen years, however, that is no longer enough, and acceptance by the peer group is paramount. Moreover, the egocentrism of childhood is gone by adolescence, leaving them able to realize that others might view them much more negatively than they see themselves. The shifting cliques and friendship patterns, combined with a slow dawning awareness of complex social rules that everyone but you seems to understand, make belongingness highly insecure and tenuous. But as Mark says, these concerns subside as one moves into adulthood and establishes some important contexts for belongingness, such as work and family. As long as one belongs securely there, there is less need to worry about being accepted everywhere.

Another big issue for future research and societal concern is what happens when the child's early years do not have a stable belongingness context? The trend in modern societies is toward more family dissolution, single and divorced parents, geographical moves, rotating quasi-stepparents, and the like. What are the lasting effects on a child of starting out life without that stability of belongingness?

8. Where Do Notions of Culture and Context Fit into Your Perspectives on Belonging?

RB: Many social animals have a kind of need to belong, in the sense that they have an innate motivation to affiliate with other members of their species. But they have little or no culture. The need to belong may have thus changed during human evolution to make culture possible, so that humans could survive and reproduce better. This has obviously worked quite well: The human population continues to grow, now approaching 8 billion, whereas most other mammals are seeing their populations decline.

Human sociality differs from that of other social animals in multiple ways, but two major themes stand out: cooperation and communication. I have argued elsewhere (Baumeister \& Masicampo, 2010) that communication should be considered the original and essential human trait, rather than intelligence as the name homo sapiens implies. Increases in brain size and intelligence are not necessarily adaptive, especially given that brains are metabolically costly. The human brain is about $2 \%$ of the body mass but accounts for $20-25 \%$ of its total caloric energy consumption. A 
rodent with a giant Einstein brain would probably starve to death because the extra brainpower would not bring in enough extra calories to keep itself going. Dunbar's social brain hypothesis, based on comparing brain size across many species (and not even including humankind), holds that larger brains were mainly associated with more advanced social networks and social interactions. Human evolution took this to an extreme by virtue of communication. Sharing information gives each brain plenty more to work with, eventually enabling science, technology, and medicine, along with all the improvements in quality and quantity of life that these enabled.

Thus, one likely refinement in the evolution of the human need to belong involved the urge to communicate. Suddendorf's (2013) thoughtful analysis of the gap between humankind and other species emphasizes two human innovations, one of which is that humans have a seemingly innate and pervasive urge to communicate their thoughts to others (the second is recursion, which is not relevant here). In retrospect, this should not be all that surprising, given that one thing people do together almost universally is talk.

In terms of the need to belong, the urge to communicate suggests that human evolution has moved far beyond any simple "herd instinct" or craving for affiliation. In my recent work, I have come to speak of the human self as partly an information agent, that is, a being whose social interactions are often permeated by trafficking in information. Many animals are curious (seeking information), but that's about it. Humans share what they find, pass along information from others, criticize and argue so as to refine information, cultivate shared reality, sometimes disseminate false information, and more. The need to belong is still there, but it's more than just sitting together. The informational give and take constitutes much of the everyday practice of belonging.

ML: Although little cross-cultural research on the need to belong has been conducted, culture seems to play an exceptionally important role in prescribing ways to enhance acceptance and belonging by other people. A universal aspect of socialization involves learning local norms regarding how one should behave to promote acceptance and avoid rejection by other people. At a broad level, similar criteria apply as people learn to develop competencies that others value. For example, they interact with other people in socially prescribed ways and behave in ways that show they are an ethical, trustworthy social exchange partner. But the specific behaviors that increase the probability of acceptance and belonging are often culture- and context-specific, receiving approbation from one group but rejection from another. In a global society, such differences are increasingly important, being a frequent source of misunderstandings, offense, and conflict.

9. A Focus on Belonging Is Sometimes Criticized for Creating Notions of Exclusion or Othering, Where People Who Are not Seen to Belong to a Group and Are Treated Differently or Made to Feel Like an Outsider. How Do You See ModernDay Belonging Research and Discourse Fitting in with Work on Inclusion, Diversity, and Equity?

ML: It's a fact of human nature that people do not value everyone equally as relational partners and group members. In fact, evolutionary psychologists 
suggest that the human brain isn't designed in a way that even allows us to have equally fulfilling relationships with everyone we meet; I'm particularly struck by the notion that we have a finite number of niches or slots for various kinds of relationships. So, we must begin any discussion of inclusion, diversity, and equity by acknowledging that exclusion and rejection are an ongoing, inevitable part of social life. Even in an ideal world in which we fully "accepted" every person equally as a human being, we're still going to associate with people differentially based on interests, beliefs, values, skills, and other characteristics.

But that's not the problem anyway. The problem is not that people don't value their relationships with everyone equally or that they don't allow everyone who wants to join all of their groups to become a member, which is impossible. The problem is that our reactions to other people vis-à-vis belonging and acceptance are affected, often implicitly, by characteristics that have nothing to do with a person's actual relational value as a friend, acquaintance, partner, co-worker, or group member - such as their skin color, gender, or nationality. As a result, people often turn their backs on people they might like to know and unfairly disadvantage them in a number of ways.

The issue, then, is how to reduce the degree to which people's reactions to others vis-à-vis social acceptance and belonging are affected by - if not based on — irrelevant characteristics. Research is needed on how people make judgments about other people's social acceptability — not just the characteristics that influence those judgments (which has been the focus of much research on prejudice and discrimination) — but the more fundamental processes involved in assessing whether other people should be accepted as members of our social circles.

In addition, interventions designed to enhance inclusion and an appreciation for diversity might benefit from leading participants to construe prejudice and exclusion of outgroup members as a maladaptive, self-defeating behavior. In addition to being unjust, basing decisions about acceptance and belonging on irrelevant characteristics leads people to make bad decisions in their selection of friends and group members.

10. Are There Aspects About Your Perspective on Belonging that Are Misrepresented, Misunderstood, or Underappreciated?

ML: Some researchers think that we overstated the power and pervasiveness of the need to belong as a fundamental social motive. As evidence, they sometimes point to all of the things that people do that undermine their belonging and acceptance, arguing that these counterexamples show that belonging isn't actually as important as we suggest. For example, some have asked why people are prejudiced and reject outgroup members, actions that obviously don't endear us to those we reject. Others have pointed out that we often treat other people in hurtful ways that lead them to reject us, do things that damage our closest relationships, and even behave aggressively toward others who reject us, all which seem counterproductive if our goal is to be accepted and belong. If belonging and acceptance are so important, shouldn't we want to be socially connected to everyone and always behave in ways that promote acceptance? 
But Roy and I never suggested that people are motivated to be accepted by everyone at all times or that other motives don't play a role in human behavior. Many behaviors that undermine our social connections and diminish belonging are tradeoffs in which we sacrifice belonging to get some other valued outcome. In addition, some behaviors that undermine belonging might actually reflect a desire for acceptance at their core. For example, being prejudiced against outgroup members may strengthen connections among members of one's own group, and aggressive reactions to rejection are sometimes intended as a deterrent against future rejection. And people regularly engage in antisocial, even illegal behaviors that might result in rejection because those behaviors promote their belonging in antisocial groups.

I also think that we underestimate the number of times that behaviors that lead to lowered belonging or rejection are miscalculations or the result of poor interpersonal skills. We've all behaved in ways that undermined our acceptance because we didn't accurately anticipate how others would react or badly mismanaged an interpersonal encounter.

So, although we maintain that belonging is the most important social motive - the social motive that influences more human behavior than any other - we have never suggested that it's the only motive or that people don't undermine their belonging for a variety of other reasons.

RB: I'd like to amplify Mark's point that rejecting others may strengthen one's ties to one's ingroup. Belonging to all humankind is not the point and probably is contrary to the evolutionary basis for belonging. There's "no us without them" in the common phrase. This was confirmed most recently in Moffett's (2018) book The Human Swarm. It's normal and natural to have enemies and outgroups. Meanwhile, recent research linking online mobs that target people to "cancel" them by ruining their reputations are likewise driven by striving to impress one's ingroup.

\section{What Scholars Have Inspired Your Work, and Why?}

ML: A great deal of my work has been inspired greatly by my mentor, Barry Schlenker, who constantly stressed that most social behavior is motivated by interpersonal rather than intrapersonal motives. That point might seem obvious, but historically, social psychologists have tended to rely heavily on explanations that involve internal motives to create some internal cognitive or emotional state, such as motives to seek cognitive consistency, self-esteem, or a feeling of control. Much of my work has been an effort to keep the "social" at the forefront of social psychology, emphasizing that most behavior is directed toward social goals, including the goal to belong (Leary et al., 2015).

Perhaps the person I've cited most over the years is William James, whose early discussions on self and identity, motivation, and emotion have provided a foundation for much of my research. I also developed a greater affinity for James when I read his letters in which he grumbled about spending too much time on administrative matters, agonized over impending publication deadlines, and griped about problematic university administrators and faculty members.

I also want to acknowledge that Roy has also inspired me a good deal, particularly in terms of the breadth of his thinking. Whereas many psychologists myopically 
zero-in on the topics they study, Roy regularly steps back with a wide-angle lens, looking at the topics he studies from the broadest possible perspective.

RB: I shudder to answer this because I know I will unfairly leave some names off. Many have inspired me. Sigmund Freud inspired me to go into psychology. At age 18 I was majoring in philosophy at a great German university, and I read lots of moral philosophy, but then I was dazzled by a couple of Freud's books. It was his approach more than the specific conclusions: you could study morality, not just by thinking carefully about the ideas, but by looking at scientific data about how people actually learn their morals and act on them — wow! So, I majored in psychology. I developed the vague plan that I would address the big philosophical questions, or at least a goodly bunch of them, using social science data.

In my career, I was greatly aided and inspired by my mentors, including the great Edward E. Jones, and Joel Cooper, who has continued to inspire (Ned is long dead). Others who helped me in early career stages were Douglas Detterman, Robert Hogan, Robert Sternberg, Robert Baron, Steve West, and really countless more. As for role models, early in my career, I looked up to Shelley Taylor and Bob Zajonc, and for the late years, my role model is Arie Kruglanski. Ten years from now, I want to be just like him: doing great work, connected to lots of bright people, thinking big thoughts, publishing in the top journals, and having plenty of fun along the way.

In terms of authors I read who inspire me, most of whom I have never met, and to keep the list manageable, I will limit it to people who have done multiple books or works that have changed my thinking, not just one: I would list Francis Fukuyama, Robert McNeill, Michael Tomasello, Steven Pinker. If you haven't read anything by them, you're missing out. As to why: Fukuyama and McNeill have provided careful, thoughtful analysis of big-picture developments in human cultural history. Tomasello has written extensively about humans and animals, not falling into either the trap of saying they're pretty much the same or completely different, but instead rigorously noting both similarities and differences. Pinker has also written fine books tackling a series of big issues and ideas.

12. From Your Perspective, What Basic, Applied, or Methodological Questions About Belonging Remain Unanswered?

ML: Wow, there are dozens of unanswered questions. One of the most important involves how people assess their level of belonging within a particular group or their level of acceptance by a particular person. In most experimental studies, we provide participants with rather explicit information about others' reactions to them, but in everyday life, people often draw inferences about the strength of their social connections from a large number of cues, many of which are quite subtle and ambiguous - a look of disinterest, an unreturned call, a critical remark. In many instances, people must draw inferences about how a group feels about them - the members of which may differ in their views - to develop a general sense of the degree to which they belong to the "group." And, whether people are dealing with the reactions of an individual or a group, these inferences are influenced by their assumptions about themselves and about other people, as well as by features of their personality. How do people put all of these cues together to conclude that they do or do not adequately 
belong? And how do they distinguish innocuous disinterest or unintentional exclusion from actual rejection?

Along the same lines, people's attributions for instances of rejection affect their reactions. How do people identify the cause of the problem - whether it reflects something about their acceptability or something about those who are rejecting them? These attributions are also linked to people's implicit theories about the general bases of belonging and acceptance - people's beliefs about what they need to do in order to belong - as well as to their beliefs about why people are rejected by others.

The inferences people make about their belonging, and their understanding of why they do or do not belong, play a very important role in their reactions and are important aspects of interventions designed to increase belonging. Yet, we know almost nothing about how people wade through all of the incoming social signals to draw conclusions about the degree to which they are accepted and belong.

RB: Lately, I have been waking up to the importance of time. Most animals just live in the eternal present, but human life constantly integrates past, present, and future.

For example, one thing I wondered about the rejection research is why people seemed so affected by our small laboratory rejection manipulations. One of these involves telling people that no one else in the group of strangers chose you as someone to work with. So what? You never met these people before and likely will never see them again, so why should their rejection matter to you? But in a recent paper (Sjåstad et al., 2021), we found that being rejected now functions as a warning sign that you are likely to be rejected by others in the future. It's the future that's upsetting.

Another time-related issue concerns long-term effects. We found plenty of evidence that the immediate effect of unexpected rejection is a kind of emotional and physical numbness: the emotion system just sort of shuts down, and sensitivity to pain diminishes (DeWall \& Baumeister, 2006). But this is presumably temporary, a kind of shock reaction. Long-term effects of frequent rejection might use up this coping mechanism, leading to worse results. For example, people who were frequently rejected as children might end up having more aches and pains as adults, and perhaps being more upset about adult rejections. I've seen unpublished data suggesting that pattern, but someone should investigate it properly.

\section{Where Do You See the Future of Belonging Research Heading?}

ML: I'm not a good person to ask because, if you had asked me that question when we published our need to belong article in 1995, I would have been totally wrong. I couldn't have imagined that we'd see an explosion of work on this topic that would continue for more than 25 years and show no signs of slowing down.

I think the widespread interest in the need to belong over the past 25 years reflects the fact that, once researchers began to examine topics related to belonging and acceptance, they saw the effects of this motive everywhere. No matter what else people may be doing, they seem to keep one eye on their connections with other people. Even when focused on other things, it takes very little to draw people's 
attention to what others are thinking about them and evoke strong concerns with belonging and acceptance.

Given the power and pervasiveness of concerns with belonging and acceptance, I assume that future researchers will continue to venture into unexplored areas of life in which the need to belong is relevant and delve more deeply into the processes by which people seek belonging and acceptance and deal with the inevitable threats of rejection that arise.

RB: I think Mark is the best person to ask about this (I just read his response). Or I can't think of anyone who would know better than he does, unless perhaps the editors of a major book or special issue devoted to belongingness. As for myself, I don't have my finger on the pulse of the belongingness research community. But in terms of likely directions, I could suggest two. First, given what we know, what sorts of interventions might be effective? It is safe to say belongingness is mostly a good thing, so it's appropriate to put this into practice. There is a lot of loneliness and rejection out there - can we come up with effective strategies to strengthen actual belongingness (or at least feelings of inclusion and belongingness)? Second, in the US the recent upsurge of identity politics suggests a new form of tribalism, which may well spread to Australia, Europe, and other cultures. Tribalism is an atavistic form of belongingness and may be replacing patriotism, a fairly modern though not necessarily desirable form, for better or for worse. Future research on modern tribalistic belonging might reveal important new dimensions as well as shedding light on one of the grand historical trends of the present time.

\section{What Advice Would You Give the Next Generation of Belonging Research-} ers?

ML: The most important thing is to be careful and precise in the constructs and terms that you use in your work and to be sure that your measures and manipulations map on to those conceptualizations as tightly as possible. Because there were no standard conceptualizations or operationalizations of constructs related to belonging and acceptance at the time we wrote our 1995 article, the first generation or two of belonging researchers - myself included - used a hodge-podge of terms in imprecise and inconsistent ways that created a conceptual muddle from which the field still hasn't entirely emerged. Perhaps the best example is the fact that many of us used "exclusion" and "rejection" as if they were synonyms, which isn't the case. People can be excluded without feeling rejected.

Several years ago, I tried to bring some order to the conceptual quagmire by suggesting that all experiences that include a sense of being rejected involve the perception that one has low relational value to one or more other people (and sometimes to an entire group). Relational value is the degree to which people regard their relationship with a person as important, valuable, or close, so perceiving that one's relational value is lower than desired evokes a sense of rejection, along with reactions such as hurt feelings and lowered self-esteem. Perceived low relational value is a component of a variety of social experiences, including rejection, ostracism, romantic breakups, expulsions from groups, being ignored, stigmatization, prejudice, discrimination, loneliness, and many (but not all) incidents of exclusion. These 
are different kinds of interpersonal events, and I'm not suggesting that they are all the same thing. But the concept of perceived low relational value provides a way to think about the various ways in which problems with belonging and acceptance can manifest.

My second suggestion is to explore the distinct processes that are involved in the quest for belonging and acceptance more fully. The bulk of research thus far has focused on the impact of low belonging, rejection, ostracism, or exclusion on people's emotions, self-views, and behavior. But we know less about how people: assess their degree of belonging and acceptance, make attributions about why they have low relational value in a particular situation, draw inferences about themselves based on rejection experiences, and determine the best way to deal with such situations (for example, should I try harder to be accepted, strike out in anger, or just go away?).

My third suggestion is to study these questions in the context of people's ongoing social lives-at work or school, in their peer groups, in the community, or wherever. Most research on rejection over the past 25 years has involved either questionnaire studies or lab experiments, with little attention to how people navigate problems with belonging and acceptance in their daily lives. In particular, more experience sampling studies are needed to understand the quest for belonging in vivo.

RB: I agree with Mark on the desirability of getting data from daily life. Unfortunately. social psychology is moving in the opposite direction, with most studies now involving online samples (e.g., MTurk) in which people simply recall or imagine things and then make some mental response. But the rise of big data may help. Learning about people across the lifespan is important, given the earlier point that late adolescents (such as the student populations used in much research) may be especially sensitive and vulnerable to belongingness issues.

Also, I tend to see the world in terms of trade-offs. Belongingness has many good aspects, but surely there are some downsides. This may be something worth exploring. Does the need to belong produce destructive behaviors?

\section{Inter-generational and Interdisciplinary Benefits of Belonging Research}

There are several important take-aways from this inter-generational scholarly dialogue on belonging that are relevant for the interdisciplinary nature of educational psychology (Allen, 2021). The human desire to belong is age-old; historically serving as a survival mechanism for groups over time. Conceptualizing belonging, therefore, requires that scholars acknowledge its protective function, while also striving to develop frameworks at the right altitude - that is, ones that are neither too broad or too narrow in nature. Like many other concepts in educational psychology, theoretical perspectives on belonging are greatly influenced by scholars outside of our field. Baumeister and Leary's social psychological perspective provides a more global, macro interpretation of belonging that has been widely cited in educational psychology to justify why belonging is important to study in schooling contexts, yet over time, the constructs that educational psychologists borrow from other disciplines 
evolve to take on new meanings within our discipline (Berliner, 1992). The study of school belonging will likely follow a similar trajectory with more grounded, situative, and participatory understandings emerging from our school-based research. To this end, the reflections in this article position the next generation of educational psychologists to expand upon, modify, or even resist the application of macro-perspectives of belonging processes in educational settings.

As psychologists, we often study social and cognitive processes at the level of the individual, yet this conversation reminds us that these processes serve interpersonal functions. In addition, social contexts can be structured in ways that afford opportunities for healthy interpersonal dynamics to take place, allowing for instructional and institutional opportunities to belong at school (Gray et al., 2018). Because school policies and practices impact students differently depending on the social identities they embrace, scholars are encouraged to further examine the role of culture and social identity in belonging processes as they operate in academic contexts (Allen et al., 2021d). Technology has also added a level of complexity to students' belonging experiences, with social media having both positive and negative influences on adolescents' belonging experiences in online and in-person contexts (Allen et al., 2014; McCahey et al., 2021; Ryan et al., 2017). Belonging researchers are therefore encouraged to consider-and provide guidance on-the way belonging experiences can be cultivated to promote positive personal and social outcomes for students. Researchers of school belonging also have yet to investigate how the salience of different levels of self-representation (i.e., personal, relational, collective levels of the self; see Brewer \& Gardner, 1996) contribute to self-judgements and achievement behavior when students experience confirming or disconfirming messages about their belonging at school. Finally, considering the recent attention in educational psychology on more culturally derived and equity-focused perspectives and frameworks, the belonging theorists with a diverse positionalities (i.e., international perspectives, ethnicity, gender, et cetera) can build on Baumeister and Leary's foundational research in ways that critically examine our understanding of the context and culture-specific aspects of belonging processes moving forward.

\section{Concluding Remarks}

What does belonging represent to scholars who have pioneered rigorous investigations into this construct, and what implications do their interpretations have for educational psychologists? Is school belonging a direct theoretical extension of social psychological perspectives on belonging? In what ways does a macro perspective on belonging expand the way in which educational psychologists consider the potential impact of school belonging on broader societal dynamics?

In this article, we have attempted to offer an in-depth perspective on belonging by tracing the concept back to the foundational work of the scholars who helped highlight the fundamental importance of this psychological need. In so doing, we sought to highlight belonging's broad societal applications, while also highlighting additional areas of exploration that are specific to the work of educational psychologists. The continued quest for a deeper understanding of school belonging takes us beyond 
the acknowledgement of belonging as a basic human need to a more textured understanding of how school belonging can be conceptualized, studied, and applied have the greatest positive impact in schools. We hope this reflective account explicates some assumptions about belonging, inspires belonging researchers to dream big about their broader impact, and invites new perspectives that pluralize and diversify educational psychology's contribution to belonging-centered policies and practices.

\section{References}

Abdollahi, A., Panahipour, S., Tafti, M. A., \& Allen, K. A. (2020). Academic hardiness as a mediator for the relationship between school belonging and academic stress. Psychology in the Schools, 57(5), 823-832. https://doi.org/10.1002/pits.22339

Alexander, H. (2021). Student was not victim of racism for 'eating while black' at \$80k Smith College and made up details that ruined the lives of four campus workers and led to controversial anti-bias training that employee resigned over. Mail Online. https://www.dailymail.co.uk/news/article-92974 75/Black-student-not-victim-racism-eating-black-80k-Smith-College.html. Accessed June 202.

Allen, K. A. (2020a). The Psychology of Belonging. Routledge (Taylor and Francis Group).

Allen, K. A. (2020b). Commentary of Lim, M., Eres, R., Gleeson, J., Long, K., Penn, D., \& Rodebaugh, T. (2019). A pilot digital intervention targeting loneliness in youth mental health. Frontiers in Psychiatry. https://doi.org/10.3389/fpsyt.2019.00959

Allen, K. A., \& Bowles, T. (2012). Belonging as a guiding principle in the education of adolescents. Australian Journal of Educational and Developmental Psychology, 12, 108-119.

Allen, K. A., Kern, M., McInerney, D., Rozec, C., \& Slavich, G. (2021a). Belonging: A review of conceptual issues, an integrative framework, and directions for future research. Australian Journal of Psychology, 73(5), 1-16. https://doi.org/10.1080/00049530.2021.1883409

Allen, K. A., Arslan, G., Craig, H., Arefi, S., Yaghoobzadeh, A., \& Nia, H. S. (2021b). The psychometric evaluation of the sense of belonging instrument (SOBI) with Iranian older adults. BMC Geriatrics, 21(1), 1-8. https://doi.org/10.1186/s12877-021-02115-y

Allen, K. A., Jamshidi, N., Berger, E., Reupert, A., Wurf, G., \& May, F. (2021c). Effective school-based interventions for building school belonging in adolescence: A systematic review. Educational Psychology Review, 1-29. https://doi.org/10.1007/s10648-021-09621-w

Allen, K. A., Kern, M. L., Vella-Brodrick, D., \& Waters, L. (2018a). Understanding the priorities of Australian secondary schools through an analysis of their mission and vision statements. Educational Administration Quarterly, 54(2), 249-274. https://doi.org/10.1177/0013161X18758655

Allen, K. A., Kern, M. L., Vella-Brodrick, D., Waters, L., \& Hattie, J. (2018b). What schools need to know about belonging: A meta-analysis. Educational Psychology Review, 30(1), 1-34. https://doi. org/10.1007/s10648-016-9389-8

Allen, K. A., Ryan, T., Gray, D. L., McInerney, D. M., \& Waters, L. (2014). Social media use and social connectedness in adolescents: The positives and the potential pitfalls. The Australian Educational and Developmental Psychologist, 31(1), 18-31. https://doi.org/10.1017/edp.2014.2

Allen, K. A., Vella-Brodrick, D., \& Waters, L. (2016). Fostering school belonging in secondary schools using a socio-ecological framework. The Educational and Developmental Psychologist, 33(1), 97-121. https://doi.org/10.1017/edp.2016.5

Allen, K. A. (2021). The transdisciplinary nature of educational and developmental psychology. The Educational and Developmental Psychologist, 37(1), 1-3.

Allen, K. A., Gray, D. L., Arslan, G., Riley, K., Vella-Brodrick, D., \& Waters, L. (2021d). Chapter 19: School Belonging Policy. In K. A. Allen, A. E. Reupert, \& L. G. Oades (Eds.), Building Better Schools with Evidence-based Policy: Adaptable Policy Guidelines for Teachers and School Leaders. Routledge.

Allen, K. A., Fortune, K. C., \& Arslan, G. (2021e). Testing the social-ecological factors of school belonging in native-born, first-generation, and second-generation Australian students: A comparison study. Social Psychology of Education. https://doi.org/10.1007/s11218-021-09634-x 
Anderman, L. H. (2003). Academic and social perceptions as predictors of change in middle school students' sense of school belonging. The Journal of Experimental Education, 72(1), 5-22. https://doi. org/10.1080/00220970309600877

Arslan, G. (2018). Exploring the association between school belonging and emotional health among adolescents. International Journal of Educational Psychology, 7(1), 21-41. https://doi.org/10.17583/ ijep.2018.3117

Arslan, G. (2021). Loneliness, college belongingness, subjective vitality, and psychological adjustment during coronavirus pandemic: Development of the College Belongingness Questionnaire. Journal of Positive School Psychology, 5(1), 17-31. https://doi.org/10.47602/jpsp.v5i1.240

Arslan, G., \& Allen, K. A. (2021). School victimization, school belongingness, psychological well-being, and emotional problems in adolescents. Child Indicators Research, 1-17. https://doi.org/10.1007/ s12187-021-09813-4

Arslan, G., Allen, K. A., \& Ryan, T. (2020). Exploring the impacts of school belonging on youth wellbeing and mental health among Turkish adolescents. Child Indicators Research, 13(5), 1619-1635. https://doi.org/10.1007/s12187-020-09721-z

Baumeister, R. F., \& Masicampo, E. J. (2010). Conscious thought is for facilitating social and cultural interactions: How mental simulations serve the animal-culture interface. Psychological Review, 117(3), 945-971. https://doi.org/10.1037/a0019393

Baumeister, R. F., \& Tice, D. M. (1990). Anxiety and social exclusion. Journal of Social and Clinical Psychology, 9(2), 165-195. https://doi.org/10.1521/jscp.1990.9.2.165

Baumeister, R. F., Vohs, K. D., DeWall, C. N., \& Zhang, L. (2007). How emotion shapes behavior: Feedback, anticipation, and reflection, rather than direct causation. Personality and Social Psychology Review, 11, 167-203. https://doi.org/10.1177/1088868307301033

Baumeister, R., \& Robson, D. A. (2021). Belongingness and the modern schoolchild: On loneliness, socioemotional health, self-esteem, evolutionary mismatch, online sociality, and the numbness of rejection. Australian Journal of Psychology, 73(1), 103-111. https://doi.org/10.1080/00049530.2021. 1877573

Baumeister, R. F., \& Leary, M. R. (1995). The need to belong: Desire for interpersonal attachments as a fundamental human motivation. Psychological Bulletin, 117(3), 497-529. https://doi.org/10.1037/ 0033-2909.117.3.497

Berliner, D. C. (1992) Telling the stories of educational psychology. Educational Psychologist, 27(2), 143-161. https://doi.org/10.1207/s15326985ep2702_2

Bjorklund, B., \& Daly, A. J. (2021). The ties that belong: Tie formation in preservice teacher identification networks. Teaching and Teacher Education, 97, 103223. https://doi.org/10.1016/j.tate.2020. 103223

Brewer, M. B., \& Gardner, W. (1996). Who is this "We"? Levels of collective identity and self representations. Journal of Personality and Social Psychology, 71(1), 83-93. https://doi.org/10.1037/00223514.71 .1 .83

Brooms, D. R. (2016). "I was just trying to make it": Examining urban black males' sense of belonging, schooling experiences, and academic success. Urban Education, 54(6), 804-830. https://doi.org/10. $1177 / 0042085916648743$

Cardeli, E., Phan, J., Mulder, L., Benson, M., Adhikari, R., \& Ellis, B. H. (2020). Bhutanese refugee youth: The importance of assessing and addressing psychosocial needs in a school setting. The Journal of School Health, 90(9), 731-742. https://doi.org/10.1111/josh.12935

Chun, H., Marin, M. R., Pham, A., Schwartz, J. P., \& Castro-Olivo, S. M. (2016). Psychosociocultural structural model of college success among Latina/o students in Hispanic-serving institutions. Journal of Diversity in Higher Education, 9, 385-400. https://doi.org/10.1037/a0039881

DeWall, C. N., \& Baumeister, R. F. (2006). Alone but feeling no pain: Effects of social exclusion on physical pain tolerance and pain threshold, affective forecasting, and interpersonal empathy. Journal of Personality and Social Psychology, 91(1), 1-15. https://doi.org/10.1037/0022-3514.91.1.1

DeWall, C. N., Baumeister, R. F., Chester, D. S., \& Bushman, B. J. (2016). How often does currently felt emotion predict social behavior and judgment? A meta-analytic test of two theories. Emotion Review, 8(2), 136-163. https://doi.org/10.1177/1754073915572690

Faircloth, B. S. (2021). The right to belong: A critical stance. In B. S. Faircloth, L. M., \& Gonzalez, K. R. (Eds). Resisting barriers to belonging: Conceptual critique and critical applications (pp. 32-81). Lexicon Books.

Foster, C. E., Horwitz, A., Thomas, A., Opperman, K., Gipson, P., Burnside, A., Stone, D. M., \& King, C. A. (2017). Connectedness to family, school, peers, and community in socially vulnerable 
adolescents. Children and Youth Services Review, 81, 321-331. https://doi.org/10.1016/j.childyouth. 2017.08.011

Goodenow, C., \& Grady, K. E. (1993). The relationship of school belonging and friends' values to academic motivation among urban adolescent students. The Journal of Experimental Education, 62(1), 60-71. https://doi.org/10.1080/00220973.1993.9943831

Gray, D. L., Hope, E. C., \& Byrd, C. M. (2020). Why black adolescents are vulnerable at school and how schools can provide opportunities to belong to fix it. Policy Insights from the Behavioral and Brain Sciences, 7(1), 3-9. https://doi.org/10.1177/2372732219868744

Gray, D. L., Hope, E. C., \& Matthews, J. S. (2018). Black and belonging at school: A case for interpersonal, instructional, and institutional opportunity structures. Educational Psychologist, 53(2), 97-113. https://doi.org/10.1080/00461520.2017.1421466

Hamm, J.V. and Faircloth, B.S. (2005), The role of friendship in adolescents' sense of school belonging. New Directions for Child and Adolescent Development, 61-78. https://doi.org/10.1002/cd. 121

Holloway-Friesen, H. (2019). The Role of mentoring on hispanic graduate students' sense of belonging and academic self-efficacy. Journal of Hispanic Higher Education, 20(1), 46-58. https://doi. org/10.1177/1538192718823716

Ibrahim, A., \& El Zaatari, W. (2020). The teacher-student relationship and adolescents' sense of school belonging. International Journal of Adolescence and Youth, 25(1), 382-395. https://doi. org/10.1080/02673843.2019.1660998

Korpershoek, H., Canrinus, E. T., Fokkens-Bruinsma, M., \& de Boer, H. (2020). The relationships between school belonging and students' motivational, social-emotional, behavioural, and academic outcomes in secondary education: A meta-analytic review. Research Papers in Education, 35(6), 641-680. https://doi.org/10.1080/02671522.2019.1615116

Leary, M. R., Raimi, K. T., Jongman-Sereno, K. P., \& Diebels, K. J. (2015). Distinguishing intrapsychic from interpersonal motives in psychological theory and research. Perspectives in Psychological Science, 10(4), 497-517. https://doi.org/10.1177/1745691615583132

Li, C., \& Jiang, S. (2018). Social exclusion, sense of school belonging and mental health of migrant children in China: A structural equation modeling analysis. Children and Youth Services Review, 89, 6-12. https://doi.org/10.1016/j.childyouth.2018.04.017

Lim, M. H., Allen, K. A., Furlong, M. J., Craig, H., \& Smith, D. C. (2021). Introducing a dual continuum model of belonging and loneliness. Australian Journal of Psychology, 73(1), 1-6. https:// doi.org/10.1080/00049530.2021.1883411

MacDonald, G., \& Leary, M. R. (2005). Why does social exclusion hurt? The relationship between social and physical pain. Psychological Bulletin, 131(2), 202-223. https://doi.org/10.1037/00332909.131.2.202

McCahey, A., Allen, K. A., \& Arslan, G. (2021). Information communication technology use and school belonging in Australian high school students. Psychology in the Schools. Manuscript submitted for publication. In press.

Marsh, H. W. (2016). Cross-cultural generalizability of year in school effects: Negative effects of acceleration and positive effects of retention on academic self-concept. Journal of Educational Psychology, 108(2), 256-273. https://doi.org/10.1037/edu0000059

Marsh, H. W., Pekrun, R., Parker, P. D., Murayama, K., Guo, J., Dicke, T., \& Lichtenfeld, S. (2017). Long-term positive effects of repeating a year in school: Six-year longitudinal study of selfbeliefs, anxiety, social relations, school grades, and test scores. Journal of Educational Psychology, 109(3), 425-438. https://doi.org/10.1037/edu0000144

Moffett, M. W. (2018). The human swarm: How our societies arise, thrive, and fall. Basic Books.

Organisation for Economic Co-operation and Development (OECD). (2018). What school life means for students. https://doi.org/10.1787/19963777

Palikara, O., Castro-Kemp, S., Gaona, C., \& Eirinaki, V. (2021). The mediating role of school belonging in the relationship between socioemotional well-being and loneliness in primary school age children. Australian Journal of Psychology, 73(1), 24-34. https://doi.org/10.1080/00049530. 2021.1882270

Parker, P., Allen, K. A., Parker, R., Dickel, T., Guo, J., Marsh, H. W., \& Basarkod, G., (2021). Does school belonging predict NEET Status in emerging adults? PsyArXiv. https://doi.org/10.31234/ osf.io/cbwph 
Parr, E. J., Shochet, I. M., Cockshaw, W. D., \& Kelly, R. L. (2020). General belonging is a key predictor of adolescent depressive symptoms and partially mediates school belonging. School Mental Health, 12, 626-637. https://doi.org/10.1007/s12310-020-09371-0

Pittman, L. D., \& Richmond, A. (2007). Academic and psychological functioning in late adolescence: The importance of school belonging. The Journal of Experimental Education, 75(4), 270-290. https://doi.org/10.3200/JEXE.75.4.270-292

Peng, W., Li, D., Li, D., Jia, J., Wang, Y., \& Sun, W. (2019). School disconnectedness and adolescent internet addiction: Mediation by self-esteem and moderation by emotional intelligence. Computers in Human Behavior, 98, 111-121. https://doi.org/10.1016/j.chb.2019.04.011

Powell, M. (2021). Inside a battle over race, class and power at Smith College. The New York Times. https://www.nytimes.com/2021/02/24/us/smith-college-race.html. Accessed June 2021.

Ryan, T., Allen, K. A., Gray, D. L., \& McInerney, D. M. (2017). How social are social media? A review of online social behaviour and connectedness. Journal of Relationships Research, 8(e8), 1-8. https://doi.org/10.1017/jrr.2017.13

Scorgie, K., \& Forlin, C. (2019). Promoting social inclusion: Co-creating environments that foster equity and belonging (Vol. 13). Emerald.

Šeboková, G., Uhláriková, J., \& Halamová, M. (2018). Cognitive and social sources of adolescent wellbeing: Mediating role of school belonging. Studia Psychologica, 60(1), 16-29. https://doi.org/10. 21909/sp.2018.01.749

Sjåstad, H., Zhang, M., Masvie, A., \& Baumeister, R. F. (2021). Social exclusion reduces happiness by creating expectations of future rejection. Self \& Identity, 20(1), 116-125. https://doi.org/10.1080/ 15298868.2020.1779119

Slaten, C. D., Ferguson, J. K., Allen, K. A., Vella-Brodrick, D., \& Waters, L. (2016). School belonging: A review of the history, current trends, and future directions. The Educational and Developmental Psychologist, 33(1), 1-15. https://doi.org/10.1017/edp.2016.6

Slaten, C. D., Ferguson, J. K., Hughes, H. A., \& Scalise, D. A. (2020). 'Some people treat you like an alien': Understanding the female athlete experience of belonging on campus. The Educational and Developmental Psychologist, 37(1), 11-19. https://doi.org/10.1017/edp.2020.5

Suddendorf, T. (2013). The gap: What separates us from other animals. Basic Books

Uslu, F., \& Gizir, S. (2017). School belonging of adolescents: The role of teacher-student relationships, peer relationships and family involvement. Educational Sciences: Theory \& Practice, 17, 63-82. 10.12738/ estp.2017.1.0104

Walton, G. M. \& Brady, S. T. (2017). The many questions of belonging. In A. Elliot, C. Dweck, \& D. Yeager (Eds.), Handbook of Competence and Motivation: Theory and Application (2nd ed., pp. 272-293). Guilford Press.

Zhang, H., Liu, M., \& Long, H. (2021). Child maltreatment and suicide ideation in rural China: The Roles of self-compassion and school belonging. Child and Adolescent Social Work Journal, 38, 325-335. https://doi.org/10.1007/s10560-020-00679-z

Zhang, M. X., Mou, N. L., Tong, K. K., \& Wu, A. (2018). Investigation of the effects of purpose in life, grit, gratitude, and school belonging on mental distress among Chinese emerging adults. International Journal of Environmental Research and Public Health, 15(10), 2147. https://doi.org/10.3390/ ijerph 15102147

Publisher's Note Springer Nature remains neutral with regard to jurisdictional claims in published maps and institutional affiliations. 